\title{
ACERCAMIENTO A LAS PRÁCTICAS DE LA ECONOMÍA SOCIAL, LA ECONOMÍA SOLIDARIA Y LA ECONOMÍA DEL BIEN COMÚN, ¿QUÉ NOS OFRECEN?
}

\author{
THE PRACTICES OF THE SOCIAL ECONOMY, SOLIDARY ECONOMY AND THE \\ COMMON GOOD ECONOMY, WHAT CAN THEY DO FOR US?
}

\author{
Verónica Gómez Calvo \\ Universidad de Nevada, Reno. USA/USA \\ alicante@usac.unr.edu
}

Recibido/Received: 15/02/2013

Aceptado/Accepted: 18/05/2013

\section{RESUMEN}

A lo largo de toda la historia se han conocido formas de economía solidaria que amparaban a todos sus miembros a través de la cooperación. El capitalismo, sin embargo, puso en marcha un sistema individualista que pretendía conseguir el Bien Común a través de la persecución de los propios intereses personales. Tras su fracaso para solventar ciertos problemas como la pobreza, la desigualdad, el desempleo y la destrucción medioambiental entre otros, las prácticas de la Economía Solidaria han experimentado un auge inusitado en todo el mundo que trata de dar respuesta a estas cuestiones. Este artículo nos ofrece un acercamiento a las propuestas, prácticas y aportaciones de la Economía Solidaria y la Economía del Bien Común en un entorno de crisis económica, ecológica, política y moral.

\section{PALABRAS CLAVE}

Economía social, economía solidaria, economía del bien común, alternativas económicas.

\section{SUMARIO}

1. Algunas consideraciones sobre el capitalismo neoliberal. 2. La Economía Solidaria como alternativa. 3. La Economía Solidaria como desarrollo endógeno y local. 4. Distinciones entre la Economía Social y la Economía Solidaria. 5. Enfoques de la Economía Social y de la Economía Solidaria en los países del Norte y los países del Sur. 6. Dificultades específicas de la Economía Solidaria en los países del Norte. 7. La Economía del Bien Común. 8. Conclusión. Bibliografía.

\begin{abstract}
It is well known that throughout history there have always been economic practices based on solidarity to protect all the members of the community. Capitalism, nevertheless, promoted an individualistic system that believed the Common Good would be achieved just in the course of attaining our own selfinterest. The failure to solve problems such us poverty, inequality, unemployment, environmental destruction, and so, has given a new impulse to the practices of the Solidarity Economy all over the world. This article gives us an insight into these practices, and the contributions and alternatives suggested by the Solidarity Economy and the Common Good Economy in a context of economic, ecological, political and moral crisis.
\end{abstract}

\section{KEYWORDS}

Social economy, solidarity economy, common good economy, economic alternatives. 


\section{CONTENTS}

1. Thoughts on neoliberal capitalism. 2. Solidarity Economy as an alternative. 3. Solidarity Economy as endogenous and local development. 4. Social Economy and Solidarity Economy, specific characteristics. 5. Social Economy and Solidarity Economy practices in the Northern and the Southern countries. 6. Difficulties of the Solidarity Economy practices in the Northern countries. 7. The Common Good Economy. 8. Conclusion. References.

\section{ALGUNAS CONSIDERACIONES SOBRE EL NEOLIBERALISMO}

En la academia, se definía originariamente a la actividad económica como al conjunto de actividades humanas que estaba destinada a satisfacer las necesidades básicas de la comunidad en su conjunto, teniendo en cuenta aspectos tales como la alimentación, la vivienda, la salud, la educación y la cultura, todas ellas necesarias para aumentar el bienestar humano. Desde esta perspectiva, la Ciencia Económica sería la ciencia que ayuda a la sociedad a conseguir estos objetivos, creando, distribuyendo y consumiendo racionalmente la riqueza. Con este objetivo se proponen fórmulas, y puesto que hay una limitación de recursos y competitividad por la asignación de los mismos, cada propuesta económica debe, necesariamente, ir acompañada de una decisión política y juicios de valor.

Sin embargo, en la actualidad se ha extendido la idea de que la Ciencia Económica por sí misma, sin entrar en valoraciones éticas ni políticas, puede solucionar los problemas económicos y, como consecuencia, los impactos que estos puedan tener sobre el conjunto de la sociedad. Según el modelo económico capitalista, la distribución de la riqueza se lleva a cabo de manera natural en el mercado libre, donde cada individuo acude para intercambiar "libremente" sus bienes con el objetivo de satisfacer sus necesidades. Este modelo economicista da por hecho que la combinación "libre" de la tierra, el capital y el trabajo depara los productos y servicios que necesitamos, olvidándose de que para que haya un intercambio "libre" y justo, es necesario que todos los actores partan de una situación de igualdad de poder.

Además, se basa en una ética meramente utilitarista, puesto que el bienestar común se prevé como resultado de la búsqueda egoísta que cada individuo hace en la consecución aislada de sus intereses. Como consecuencia, el fin originario de la teoría económica: el bienestar común, ha caído en el olvido favoreciendo el aumento de las ganancias a cualquier precio y desvirtuando el sentido original de la actividad económica. Esta búsqueda creciente de beneficios ha traído consigo además consecuencias indeseables en numerosos ámbitos, como el medioambiental, el laboral, productivo, comercial, y financiero.

\section{LA ECONOMÍA SOLIDARIA COMO ALTERNATIVA}

Precisamente, ante la incapacidad del sistema económico dominante para solventar ciertos problemas como la creciente desigualdad entre los países ricos y pobres, el aumento de la desconvergencia entre las clases sociales en todos ellos, la pobreza y la exclusión social y la destrucción medioambiental, han surgido en diversas partes del mundo iniciativas que proponen nuevos modelos bajo la consigna altermundista de "otro mundo es posible" y cuya bandera es pensar globalmente, actuar localmente, reformular nuestros estilos de vida, poner 
en marcha vivencias de otras formas de relaciones sociales, consumir responsable y solidariamente, y limitar la producción degradante de la naturaleza y de la salud, entre otros.

Los principios básicos en los que se basan las alternativas de la Economía Solidaria, son principalmente tres:

- El objetivo de toda economía es la satisfacción de las necesidades básicas de la comunidad en su totalidad, eliminando las bolsas de pobreza y exclusión social, y aumentando el bienestar de todos.

- Todas las actividades económicas que se lleven a cabo con ese objetivo han de ser ecológica y socialmente sostenibles, lo que significa que tienen que ser: autóctonas y autónomas, autosuficientes, reduciendo el intercambio al ámbito local y regional.

- Dichas actividades deben ser igualitarias y no discriminatorias y sujetas a las decisiones políticas de la comunidad.

Esto implica necesariamente un cambio en las estructuras políticas, organizativas y participativas de una comunidad, puesto que la comunidad debe ser capaz de organizarse, autogestionarse y decidir democráticamente. Esto implica recuperar la autonomía y la capacidad de poder decidir, es decir, de elegir el tipo de desarrollo que queremos tener y ser dueños de nuestro propio destino.

La Economía Solidaria, por otro lado, no es incompatible con el libre mercado, pero siempre que éste se limite a la circulación de productos y servicios ofrecidos por empresas solidarias, se excluya la tierra del mercado por considerarla como un bien colectivo y no incluya el trabajo humano como una mera mercancía a la venta.

Hay muchas contribuciones a la Economía Solidaria desde diversos segmentos de la sociedad y distintas prácticas, así tenemos los fondos rotativos solidarios, la banca ética, el microcrédito solidario, las cooperativas, las ferias y centros de comercialización, la agricultura familiar y la soberanía alimentaria, los asentamientos de reforma agraria, la promoción de la artesanía, el desarrollo comunitario, los movimientos de trabajadores de la calle (colectores y recicladores), etc. Todas estas formas buscan en cada país una manera de articularse en redes de organizaciones sociales que desemboquen en procesos organizativos del movimiento y en plataformas de lucha a favor del derecho a su reconocimiento.

\section{LA ECONOMÍA SOLIDARIA COMO DESARROLLO ENDÓGENO Y LOCAL}

Las diferentes prácticas de la Economía Solidaria, se incluyen dentro del ámbito del desarrollo local o territorial concebido por Alves da Silva como "un proceso endógeno de movilización de las capacidades (humanas, sociales, políticas y culturales) y aprovechamiento de las potencialidades económicas locales, con la finalidad de la mejoría de las condiciones de vida de la población, en armonía con el medio ambiente" (2006:220).

Este proceso implica, por lo tanto, la combinación de políticas públicas adecuadas a las necesidades y potencialidades locales junto con la participación activa y solidaria de la sociedad en la autogestión de su desarrollo. Esto exige cambios en las estructuras, es necesario el reconocimiento legal de que hay otras alternativas económicas dentro del propio sistema hegemónico que ayude a la construcción de un proyecto de sociedad, y a su vez, esto implica trascender la democracia puramente representativa en una democracia más directa y participativa, donde la autogestión e incluso los procesos de administración de los políticos deberían ser públicos en su integridad. 
En contraste, el sistema económico actual pone al hombre al servicio del sistema económico y no al revés. Según Vázquez (2000:26) y Gallicchio (2004:2), el modelo de desarrollo local es un modelo alternativo al modelo exógeno actual. Éste se concentra territorial e inequitativamente, se extrapola además, sin tener en cuenta el territorio, los recursos, la cultura, los saberes tradicionales, las instituciones, etc., en el que se inserta; por lo que no es posible aprovechar el potencial productivo de los distintos territorios, contribuyendo con ello, al aumento de la pobreza, pues se pierden saberes y potencialidades del lugar al aceptar desarrollarse a través de un modelo exógeno.

Este modelo además, desposee a los individuos y colectivos de toda capacidad para tomar decisiones económicas, puesto que éstas son tomadas por agentes externos al área local, mientras que en los patrones de desarrollo endógeno las variables son controladas por los mismos agentes interesados.

Garafoli (1992:3) señala que en el desarrollo local, el territorio se contempla como un factor estratégico decisivo, puesto que son sus características específicas las que facilitan las oportunidades de desarrollo, y los mismos representantes territoriales poseen una serie de características culturales locales que imprimen un sello de diferenciación en el contexto del desarrollo local.

El problema digamos, del desarrollo exógeno, es que pasa por alto un conjunto de recursos naturales, económicos, humanos e institucionales que no son aprovechados y que en realidad constituyen su potencial de desarrollo, creando además en los territorios procesos de desestructuración económica y social que supeditan todavía más el desarrollo a la acumulación de capital.

\section{DISTINCIONES ENTRE LA ECONOMÍA SOCIAL Y LA ECONOMÍA SOLIDARIA}

En Europa por otro lado, el crecimiento y la evolución del concepto de Economía Solidaria están muy ligados al desarrollo experimentado por la Economía Social y sus estructuras organizativas y empresariales clásicas. La Economía Social del siglo XIX aglutinaba principalmente a tres entidades: cooperativas, mutualidades y asociaciones, que representan el núcleo duro de la Economía Social. A partir de los años 70, volvió a resurgir con fuerza debido a la crisis del Estado de Bienestar, la falta de empleo, y el riesgo de exclusión del mercado de trabajo, esta situación originó formas dinámicas de autoempleo y reforzó la solidaridad entre los actores económicos para hacer frente a las nuevas necesidades o aquellas que no podían ser satisfechas, principalmente, las de las poblaciones más desfavorecidas. Así, han ido apareciendo múltiples tipos de organizaciones que adoptan formas jurídicas y organizaciones múltiples, a veces distintas de las formas clásicas de la Economía Social.

Estas empresas y organizaciones desarrollan su actividad entre la economía pública y la economía capitalista tradicional, combinando múltiples recursos mercantiles y no mercantiles que van desde donaciones filantrópicas, subvenciones del Estado, e ingresos mercantiles, hasta el trabajo voluntario y el remunerado. De esta manera, integran la lógica del mercado junto a la solidaridad y la redistribución, adoptando formas internas de gestión que pueden asemejarse a las empresas mercantiles o a las asociaciones cívicas tradicionales del tercer sector. "Su ética se traduce por los principios siguientes: la finalidad de servicio a los miembros o la colectividad en lugar del beneficio, la autonomía de gestión, el proceso de 
decisión democrática, y la preeminencia de las personas y del trabajo sobre el capital en la distribución de los ingresos" (Defourny, Develtere y Fonteneau, 2001:38).

Sin embargo, tras la fachada jurídica a veces encontramos actividades con fines de lucro o estructuras para-públicas. En ocasiones, hay un problema de fondo entre los principios que sustentan dichas organizaciones y la práctica real.

En la actualidad, la Economía Social se define en dos vertientes, la de mercado, en donde operan las entidades más tradicionales, y la de no-mercado, donde operan las organizaciones sin ánimo de lucro.

En el subsector del mercado, los requisitos son los siguientes:

- Se crean para satisfacer las necesidades de sus socios, habitualmente se da la condición de ser socio y usuario a la vez.

- Son productores de mercado, en el sentido de que operan en él, vendiendo productos a precios significativos y de él obtienen la mayoría de sus recursos.

- Pueden distribuir excedentes entre sus socios-usuarios, pero no en proporción al capital, sino de acuerdo con la actividad que cada uno desempeña.

Dentro de este grupo también entrarían las empresas de la economía social, las empresas de inserción laboral, y las sociedades laborales o de responsabilidad limitada, siempre que la mayoría del capital sea de los socios-trabajadores. Así mismo, y más allá de toda forma jurídica, el principio distintivo y necesario es la gestión democrática, tanto en los órganos de decisión (una persona, un voto) como en el reparto de beneficios.

En el subsector de no-mercado encontraríamos las entidades privadas, mayoritariamente asociaciones y fundaciones que ofrecen servicios a terceros (familias/hogares), que pueden comercializar en los mercados pero siempre a precios económicamente no significativos, que consiguen sus recursos mayoritariamente a través de donaciones, socios, subvenciones, etc., y cuyos excedentes, si los hubiera, pueden ser distribuidos entre los miembros. Se acepta como excepción a las empresas del tercer sector de acción social, que aunque no tienen una estructura democrática, se incluyen por suministrar bienes preferenciales o de interés general, serían las organizaciones de no-mercado a favor de las familias.

Para los que proponen este concepto de Economía Social, el principal criterio es la gestión democrática, incluyen entidades de no-mercado, pero siempre y cuando formalicen una actividad económica reconocida y lo hagan de manera democrática (con la excepción de las empresas del tercer sector de acción social).

En cuanto a las organizaciones no lucrativas, han experimentado una proliferación y aumento en la provisión de los servicios públicos que está en directa relación con la progresiva privatización de los servicios sociales. Se trata de organizaciones formalmente constituidas y privadas, separadas de los poderes públicos, aunque puedan recibir subvenciones públicas; son autónomas y con capacidad de autogobierno; no tienen fines lucrativos, no obtienen beneficios a través de comerciar en el mercado, y si los tienen, no se distribuyen entre los miembros fundadores o directivos; todos sus miembros participan voluntariamente, la adhesión a la organización es libre y existe la obligación de una parte de trabajo voluntario en la misma. Digamos que el principio discriminante de estas organizaciones es la no-lucratividad, que no restringe la entrada de otras que de alguna manera comercializan sus servicios, siempre y cuando no se distribuyan sus beneficios.

La agrupación de colectivos en organizaciones de la Economía Social se explica por el interés común de todos sus miembros. La solidaridad, el apoyo mutuo y la reciprocidad son la base del interés común por la actividad, siendo, en las organizaciones de mercado, el reparto de los excedentes entre los asociados proporcional a la participación en ésta. Sin 
embargo, no se detiene a hacer una crítica del sistema en el cual se hallan inmersas. La conceptualización de la Economía Social parte de los estatutos jurídicos de las unidades microeconómicas y ahí se detiene. Sus aportaciones más importantes son la contribución al cambio institucional a través de formas jurídicas diversas, y los primeros pasos en la democratización de la sociedad civil al crear espacios de libertad y recrear formas de solidaridad para aquellos colectivos marginados por el sector público y privado.

En contraste, la Economía Solidaria profundiza más y tiene como objetivo articular los campos político y económico, ya que sólo de esta manera se puede incidir sobre el modelo de desarrollo.

La actividad económica se ha sustraído de los principios democráticos, sin embargo, en la Economía Solidaria subyace una crítica constructiva al modelo de desarrollo que le circunda, proponiendo no sólo modelos económicos alternativos sino además buscando el reconocimiento de los modos de regulación democrática y ciudadana de las actividades económicas junto a las regulaciones del mercado y del Estado.

Laville define a la Economía Solidaria como "el conjunto de las actividades que contribuyen a la democratización de la economía a partir de compromisos ciudadanos" (Laville, 1997:127). La dimensión política es pues evidente, y sin embargo, los argumentos que se usan son muchas veces de orden económico, y no social, usando el mismo lenguaje y argumentos que encontraríamos en el lenguaje económico o jurídico. Parece ser que los partidarios de la Economía Solidaria prefieren diluir su contribución a la democracia con la finalidad de conseguir convertirla en objeto de debate público o inscribirla en la agenda pública. Uno de los retos de la Economía Solidaria es llegar a demostrar que los principios democráticos pueden ser un modo de gestión, de mediación, y de regulación económica en la producción y el consumo de bienes y servicios, al mismo nivel que el mercado o el Estado (Fraisse, 2004:2).

Las variables económicas, tales como el precio, la calidad, la empleabilidad, el nivel salarial, etc., que en la economía mercantil o administrada, aparecen como una restricción externa e impuesta a los actores económicos, están más sujetas a debate en las iniciativas de la Economía Solidaria. Por ejemplo, en los Sistemas de Intercambio Locales (SEL) la regulación de los créditos y deudas acumuladas por los miembros no se realiza a través de un banco central o prestamista, sino por un colectivo en debate. En las Finanzas Solidarias, los ahorradores se preocupan por saber para qué y cómo se invierten sus ahorros desde un sentimiento de solidaridad y ética. El Comercio Justo tiene como objetivos la búsqueda del precio "justo", y cierta reciprocidad en el intercambio, ya que hay un interés y se da a conocer la proveniencia, los modos de producción, y el precio al que se producen y comercializan estos productos. Estos son sólo algunos ejemplos que dan cuenta de lo importante que es la deliberación colectiva.

No obstante, la Economía Solidaria no sólo contribuye a la democratización de las actividades económicas, sino también a una mayor democratización de la esfera pública; ya que no puede haber una profundización en la democracia pública si antes no se contempla la democratización económica.

Además, la Economía Solidaria, que se organiza en redes horizontales construyendo cadenas productivas, auto-gestionándose y apoyándose en el principio de solidaridad, no puede sobrevivir si no se articula a su vez con otras organizaciones a diferentes niveles, desde lo local hasta lo global. Por ello, algunas grandes líneas en las que es necesario avanzar son: la democratización de la economía de mercado internacionalizada, sostener la economía de mercado territorializada, relegitimar la economía no mercantil, tomar en consideración la 
economía no monetaria y reconocer la economía solidaria; lo que implica la creación de nuevos espacios públicos a nivel regional e internacional.

\section{LOS ENFOQUES DE LA ECONOMÍA SOCIAL Y LA ECONOMÍA SOLIDARIA EN LOS PAÍSES DEL NORTE Y DEL SUR}

En la Economía Social los debates se centran en la capacidad de inserción efectiva de sus organizaciones en el mercado, los problemas de la internacionalización, la competencia con las empresas de capital, la innovación y los métodos de gestión, o su capacidad para influenciar los poderes públicos.

Sin embargo, los debates de la Economía Solidaria se centran en la construcción de modelos alternativos de economía, las alternativas al capitalismo, o las formas de combatir la pobreza y la exclusión social. Se critica a su vez la institucionalización de algunas de las empresas de la Economía Social clásica y la pérdida de los valores fundacionales del cooperativismo y el asociacionismo, que a veces no tienen un reflejo en la práctica.

Por contraste, la Economía Solidaria, en su búsqueda de alternativas, ha enriquecido la Economía Social como disciplina, incorporando nuevas temáticas e introduciendo nuevos mecanismos de cambio social. Algunos de estos debates interesantes son los siguientes: la contribución de la Economía Feminista y sus análisis del patriarcado en el marco del campo económico, el intercambio basado en el trueque o los sistemas basados en monedas locales (SELS), la incorporación de las esfera de la distribución a través del Comercio Justo y la articulación de los mercados sociales, el consumo responsable, la ampliación del ámbito financiero de la Economía Social hacia el campo de las Finanzas Solidarias y la Banca Ética, etc. Además de que la Economía Solidaria ha logrado generar una importante dinámica de crecimiento de la Economía Social a través de su organización en redes en países de África, Asia y América Latina.

Brasil es el país donde más apoyos ha encontrado y donde se encuentra el discurso más radical y político, apoyando la autogestión y el asociacionismo de las clases populares desde las mismas instancias políticas y académicas; es igualmente importante el crecimiento de las redes internacionales de la Economía Solidaria en los países de Latinoamérica. Sin embargo, el apoyo a la Economía Solidaria que se recibe desde muchos Estados no es suficiente, a veces sólo se concede como un apoyo para reforzar la inclusión social dentro de la lógica neoliberal económica, ya que la inclusión depende de su competencia en los mercados. Y aunque ha habido algunos cambios en gobiernos con un proyecto político de promoción de las mayorías sustentadas por fuerzas populares, no basta con legislaciones que apoyan algunas iniciativas ligadas a la soberanía alimentaria, el desarrollo sostenible, etc.; sino que son necesarios fondos públicos para que estas políticas tengan su contraparte en la práctica. No obstante, los gobiernos se hallan limitados por la dependencia que tienen del gran capital y de sus acuerdos con el FMI, el BM y la OMC entre otros.

En contraste, la corriente europea no tiene un carácter tan radical y se enfrenta mucho menos al modelo capitalista. Su enfoque es más micro, preocupado en analizar las organizaciones, su funcionamiento y características, las diferencias en las formas jurídicas, los sectores a los que dedica su actividad, la forma en que gestionan sus recursos, y los problemas que encuentran para sustentar su viabilidad. Por lo tanto, su preocupación no es tanto encontrar modelos alternativos como encontrar un lugar para estas organizaciones en la 
economía actual, de modo que rebaja su carga política y se centra más en el estudio de lo que se llama la Empresa Social.

Las empresas sociales adoptan las figuras jurídicas de cooperativas y asociaciones, pero también se han ido desarrollando figuras específicas en algunos países como: "empresas de interés comunitario" en Reino Unido, "sociedades cooperativas de interés colectivo" en Francia, "empresas de objetivo social" en Bélgica, "cooperativas sociales" en Italia, etc. Sin embargo, independientemente de su forma jurídica, son empresas sociales todas aquellas que satisfagan ciertas necesidades sociales, incluyéndose las cooperativas y mutualidades. Hoy en día, la Economía Social aboga por superar las limitaciones de las formas jurídicas y que se atienda más a lo esencial de las empresas: su actividad y objeto social.

Por otro lado, el potencial de cambio social que tengan estas empresas dependerá mucho de que no se quede solamente en el concepto, o que no sea apropiado por empresas interesadas sólo en utilizarlo como estrategia empresarial pero sin llevarlo a la práctica real, tal y como ocurre con la Responsabilidad Social Corporativa.

\section{LAS DIFICULTADES ESPECÍFICAS DE LA ECONOMÍA SOLIDARIA EN LOS PAÍSES DEL NORTE}

Como ya nos podemos imaginar, hay dos factores que influyen fuertemente en la aparición de prácticas de la Economía Social y de la Economía Solidaria. El primero es la necesidad, cuando grupos de individuos se organizan para intentar dar respuesta a una serie de necesidades no satisfechas. En los países del Sur sufrieron un auge debido a las dictaduras de los años 60 y 70, y en los países del Norte en los años 70 por la crisis, el retroceso del Bienestar Social y los problemas de desempleo.

Así surgieron en Europa iniciativas para cualificar a trabajadores marginados del mercado de trabajo, rehabilitar económicamente ciertos barrios urbanos, revitalizar y repoblar zonas rurales abandonadas. Algunos ejemplos son las empresas de inserción laboral en Francia o Alemania, las administraciones barriales de Francia, las cooperativas sociales de Italia, los talleres sociales y de formación en Bélgica, los negocios comunitarios en el Reino Unido, etc. De hecho, la pobreza, los sin techo, la delincuencia juvenil, el aislamiento de personas mayores, infraestructuras de ayuda a la infancia, el fracaso escolar, la degradación medioambiental, etc., siguen siendo desafíos en la actualidad.

El segundo factor más importante que contribuye a la aparición de la Economía Solidaria es la identidad colectiva y/o compartir un destino común. Se ha observado en los estudios llevados a cabo en América Latina, que los lazos de pertenencia y las relaciones de reciprocidad en las sociedades tradicionales son muy fuertes y tienen un gran impacto en la formación de vínculos para llevar a cabo prácticas solidarias. Algo muy inusual en las sociedades capitalistas de hoy en día. En el siglo XIX y en la primera mitad del siglo XX, la economía social era muy dinámica porque se basaba en colectivos de individuos con conciencia de clase y como tal, eran fuertemente solidarios. Por el contrario, hoy en día en los países capitalistas se actúa con una "conciencia parcial", que no es expresión de una conciencia colectiva fuerte, sino más bien la expresión de ciertas preocupaciones, sea respecto al medio ambiente, la necesidad de hacerse cargo de personas mayores o de personas con discapacidad, la cooperación al desarrollo, etc.

Por otro lado, ha ocurrido que cuando las necesidades acuciantes de las cooperativas y mutualidades se han podido ir solventando a través del mercado éstas han desaparecido. 
Otras veces se han convertido en algo muy diferente a su concepto fundador, pues la internalización de la competencia ejerce tal presión que algunas cooperativas grandes llegan a adoptar prácticas típicas de su sector: concentración de capital, integración en otros grupos que no son cooperativas, creación de filiales que los miembros no controlan, etc.; lo que nos hace preguntarnos sobre la posibilidad de existencia de la Economía Social una vez que se ha adquirido cierto capital y tamaño.

Con esto ponemos de manifiesto que la presión de la necesidad da un auge al desarrollo de prácticas de la Economía Solidaria, no obstante, la cohesión social y la construcción de identidades colectivas juegan un papel fundamental, y éstas son mucho más débiles en los países del Norte, donde impera el individualismo, se han debilitado las normas morales y las tradiciones, además de los mismos movimientos obreros y sindicales.

\section{LA ECONOMÍA DEL BIEN COMÚN}

La Economía del Bien Común es un sistema que integra propuestas e ideas alternativas al sistema neoliberal dominante, que han sido derivadas de buenas prácticas anteriores o elaboradas por distintos estudiosos/as, y por la organización ATTAC. Por hallarse todavía en sus inicios, la EBC se está presentando fundamentalmente como un movimiento empresarial que persigue la reorientación de los objetivos de las empresas; no obstante, es un modelo integrador de diversas propuestas y tiene objetivos en distintos planos de actuación: económico, político y social.

Empezó como movimiento en Octubre del 2010; sin embargo, en poco tiempo ha conseguido llamar la atención poderosamente, habiéndose organizado ya 820 empresas en 15 países distintos, y en al menos 5 países: Austria, Alemania, Suiza, Italia y España, se han ido formando hasta la fecha unos 70 grupos de trabajo para dar impulso a este movimiento.

La EBC pone en el núcleo de su propuesta la resolución del conflicto actual entre los valores del sistema económico dominante y los valores que la sociedad estima fundamentales en las relaciones humanas. Si ésta promueve valores tales como la honestidad, la empatía, la confianza, la cooperación, la solidaridad, etc., el sistema económico neoliberal propone e incentiva, por su mismo funcionamiento, valores que en nuestras relaciones personales encontraríamos como indeseables y perjudiciales. Se considera que la meta de toda actividad económica debe ser la maximización de beneficios, sin tener en cuenta el cómo se obtienen ni las consecuencias que de ello se derivan, promoviendo para ello la competencia y el interés individual, pues predica que de este comportamiento se derivarán mayores beneficios para todos, a pesar de que los datos corroboran lo contrario.

La EBC quiere acabar con esta dicotomía que escinde a los seres humanos entre dos sistemas de valores incompatibles: uno, el que aplicamos en nuestras relaciones sociales y humanas, y otro que también experimentamos diariamente como consecuencia de haber implantado un sistema económico basado en la competitividad y la maximización de beneficios a toda costa.

Al igual que plantea la Economía Solidaria, la EBC coloca las prácticas de la actividad económica al servicio del hombre y no al revés. Hace hincapié en la incoherencia en la que se ha caído al medir el éxito económico sólo por su valor monetario olvidando medir lo fundamental, que es la satisfacción de las necesidades humanas, cayendo en el error de medir el medio en lugar de la finalidad del sistema económico: su utilidad social. 
La EBC presenta en realidad un modelo económico de mercado pero no al estilo tradicional capitalista sino "cooperativo"; se sigue basando en las empresas y la creación de riqueza, pero no sólo económica y a cualquier precio. Para ello propone que las empresas, además de realizar un balance financiero, realicen un Balance del Bien Común. En la EBC el principal valor es la dignidad humana, sustentada en que todos los seres humanos somos seres con el mismo valor; su contrapartida colectiva se hallaría en el Bien Común, y propone medir su contribución a estos valores si queremos que la actividad económica sea una actividad al servicio del ser humano.

La matriz del Balance del Bien Común (BBC) propone 17 criterios positivos y 16 criterios negativos que se han de medir y que se pueden aplicar a cualquier empresa (privada o pública), banco, organismo (público o privado) y se asientan sobre 5 valores principales que su fundador, Christian Felber, encontró presentes en todas las constituciones estudiadas y leyes fundamentales: dignidad humana, solidaridad, sostenibilidad ecológica, justicia social y participación democrática y transparencia. Los criterios asentados sobre estos 5 valores se desglosan según los grupos de personas afectadas por las actividades empresariales, éstos son: proveedores, financiadores, empleados/propietarios, clientes/productos/servicios/co-empresas, ámbito social: región, soberanía, generaciones futuras, personas y naturaleza mundial. Las matriz del Bien Común tiene en su eje horizontal los cinco valores señalados antes y en su eje vertical a los grupos afectados por la actividad empresarial, en las intersecciones aparecen criterios que miden múltiples aspectos, entre ellos: hasta qué punto son útiles los productos/servicios, cómo son las condiciones laborales, hasta qué punto se produce ecológicamente, cómo se reparten los ingresos, si se toman las decisiones en la empresa de forma democrática, si hombres y mujeres son remunerados de igual manera, etc.

Cientos de empresas se han implicado en la elaboración de esta matriz que ya se puede aplicar, aunque se sigue contando con el trabajo de las mismas, particulares y organizaciones, que comparten su experiencia y conocimiento para ir madurándola.

El objetivo es que una vez que se disponga de una matriz representativa, precisa y fácil de usar, se convoque una asamblea económica para formular una normativa económica que sea aprobada democráticamente y recogida en la constitución. El Balance del Bien Común debería ser pues, un balance susceptible de actualizarse y ajustarse en cualquier momento determinado según la soberanía popular, con lo que se cumpliría otro de los objetivos perseguidos por las economías solidarias, y es la democratización de la economía.

Según lo visto hasta ahora, el Balance del Bien Común es un instrumento que mide cómo las actividades de las empresas $\mathrm{u}$ organizaciones funcionan y afectan a los distintos grupos con los que se interrelaciona según una serie de valores universales y fundamentales. De esta manera, se propone un instrumento real que pueda medir cómo la actividad económica afecta al mundo que le rodea, a la vez que sirve a las mismas empresas como instrumento de autoevaluación y progreso en su camino de reorientación de valores y objetivos.

La novedad de esta propuesta es que por primera vez se ha diseñado un instrumento que mide el Bien Común que la actividad empresarial genera, que invierte el orden, las prioridades y finalidad de las mismas, y contribuye a que se cumplan las máximas que predica la Economía Solidaria: el hombre debe ser el centro del sistema económico, éste debe estar a su servicio contribuyendo a la satisfacción de sus necesidades básicas y aumentando su bienestar; además, dichas actividades económicas deben ser ecológica y socialmente sostenibles; igualitarias y no discriminatorias y sujetas a las decisiones políticas de la comunidad. Según Christian Felber: "Una sociedad democrática debe estar en posición de formular y exigir o respaldar a las empresas de diez a treinta expectativas centrales, y 
fomentarlas mediante los mecanismos de incentivación propuestos" (Felber, 2012:57), visión compartida por las demás prácticas de la Economía Solidaria, según la cual las asambleas democráticas populares son, indudablemente, un mecanismo legítimo de regulación de la actividad económica.

El BBC debe ser auditado por auditorías externas preparadas para este fin y sus resultados publicados obligatoriamente, de manera que los consumidores tengan información relevante sobre las empresas, los productos y servicios a los que acceden. Este es un aspecto de considerable importancia, sobre todo si tenemos en cuenta que con las elecciones que hacemos cuando consumimos estamos apoyando un determinado modelo económico. Al consumir estamos colaborando en todos los procesos que hacen posible el bien o servicio consumido. Estos procesos tienen implicaciones de carácter económico, social y medioambiental, el consumidor debería ser consciente de los mismos para poder elegir responsablemente pero esto es algo utópico en la actualidad, pues el consumidor no dispone de dicha información y se deja recaer toda la responsabilidad para su obtención sobre él mismo. El Balance del Bien Común resuelve esta situación, pues tras la primera auditoría se adjudica un logo distintivo del BBC y sus resultados se pueden leer gracias a una especie de código de barras que se abre y desglosa a través de los móviles de los clientes. De esta manera, el consumidor tiene la información que necesita y puede ejercer su derecho de participación y su responsabilidad individual y colectiva en las compras que realiza.

Así mismo, el movimiento de la Economía del Bien Común tiene como otro de sus objetivos la creación de un marco legal vinculante que recompense a estas empresas éticas y responsables frente a aquellas que no lo son. Esto se podría realizar a través detasas de impuestos reducidas, tasas de aduanas reducidas, créditos con interés reducido, prioridad en la compra pública, cooperación con la investigación universitaria, etc.

En cuanto a los beneficios, considera que éstos no deberían ser el objetivo prioritario, aunque sean importantes, y establece una distinción entre usos positivos de los mismos, como inversiones (con plusvalía social y ecológica), repago de créditos, retención de reservas, distribución a personas que crean la plusvalía (es decir, según su trabajo y no por ser las dueñas del capital aportado) y créditos sin interés a co-empresas; y usos negativos de los beneficios que no deberían estar permitidos, como las inversiones financieras, tragarse otras empresas, distribución a personas que no crean plusvalía, donaciones a partidos políticos; es decir, todas aquellas acciones que no deparan riqueza al bien común y degeneran en comportamientos irresponsables y egoístas que lo dañan.

Además con esta diferenciación en el uso del superávit, las prioridades de las empresas se invertirían porque alcanzar la maximización del beneficio no sería ni un objetivo necesario ni deseable, ya que al no basarse el sistema en la competencia y el beneficio, no sería necesario crecer indefinidamente para competir y no ser tragado por otras empresas, con lo que sólo tendrían que crecer hasta obtener su tamaño óptimo.

En cuanto al sistema financiero, la EBC necesita de una banca democrática orientada al bien común, sus valores y objetivos deberían ser los mismos que guían a la $\mathrm{EBC}$, fomentando en particular los circuitos económicos regionales y las inversiones sostenibles desde un punto de vista social y ecológico y cumpliría, entre otras cosas, con tareas esenciales a las que ya casi no se dedica la banca, como la concesión de créditos accesibles para empresas y hogares locales. Por ello, la creación de una Banca Democrática es otro de los objetivos prioritarios de la EBC.

También hace especial hincapié en el desarrollo de la democracia, pues en una democracia real el pueblo debería ser soberano, cosa que no ocurre en la actualidad. Para ello, el pueblo 
tendría que tener la posibilidad real de: elegir un gobierno concreto, desechar a ese gobierno si no cumple con su programa, corregir al Parlamento en un anteproyecto de ley si no está de acuerdo con él, el mismo pueblo soberano debería proponer leyes a votación, modificar la Constitución por iniciativa propia, votar directamente una asamblea constitucional, controlar y dirigir los servicios públicos básicos más importantes. También aboga porque el pueblo sea consciente de que estas son las herramientas que necesita para ser realmente soberano y por una implantación más evidente y consecuente del principio de la separación de poderes, $\mathrm{y}$ propone por todo ello una serie de pasos concretos hacia una democracia tridimensional que albergaría: una democracia indirecta o representativa, una directa y una participativa.

De todos modos, éste es sólo el principio del camino, y la misma EBC sugiere que es un modelo abierto que debe ser combinado y enriquecido con otras propuestas y modelos alternativos, como la Economía Solidaria, el bien comunal, la democracia económica, la economía del regalo, o la economía del decrecimiento, entre otros, para dar respuestas a las necesidades y promover el bienestar del ser humano según sean necesario en cada lugar y consensuado democráticamente.

\section{CONCLUSIÓN}

Las prácticas de la Economía Solidaria y la EBC devuelven a la economía su verdadera finalidad: proveer de manera sostenible las bases materiales para el desarrollo personal, social y ambiental del ser humano en cada territorio. Se basan en valores universales que deben regir la sociedad, como la equidad, la justicia, la fraternidad económica, la solidaridad y cooperación social y la democracia directa. Pero además, conllevan el germen de la auténtica revolución y transformación social.

El poder popular no se presenta como un "contrapoder" sino como un proceso integral de gestación de nuevos valores y relaciones, ya que la superación del capitalismo requiere de la superación de la lógica del funcionamiento del capital, y esto significa que la transformación social requiere de una larga transición. Esta empieza cuando los pueblos tratan de dar respuesta a sus necesidades y para ello se organizan proponiendo alternativas, impulsando la participación democrática y organizándose políticamente, construyendo de esta manera, un poder político-cultural popular desde abajo.

Se trata de un proceso integral de transformación consciente y activa del actor colectivo que es protagonista del cambio y que se va gestando así mismo y gestando una nueva realidad en este proceso. Ya que abarca todas las áreas de la vida, no es que sean necesarios primero los cambios en lo económico y después en lo cultural, y así sucesivamente en otras áreas, sino que todas las áreas de la vida están interrelacionadas y por lo tanto, el auténtico cambio implica transformaciones que inciden a la vez en todas ellas.

La vía democrática de transformación social implica que en cada momento del proceso haya que optar a favor de quiénes y de qué políticas estamos, y desde dónde, quienes gobiernan y para quién. Esta debería ser siempre una opción consciente del pueblo, individual y colectiva; y para que así ocurra, hay que construirla diariamente desde abajo. Por ello, la realización de asambleas constituyentes es vital, como vemos en los ejemplos de prácticas de la Economía Solidaria de muchos países de Latinoamérica, todos los pueblos deberían poder ejercer su derecho a expresar sus puntos de vista e intereses en un proceso permanente. 
Lo que aparece en la Economía Solidaria y la EBC es una nueva cultura de poder basada tanto en la participación colectiva creciente en el proceso de toma de decisiones como en la ejecución de las resoluciones y el control de los resultados y la gestión gubernamental toda; y para conseguirlo, es necesario el empoderamiento creciente de los individuos y de los pueblos.

Si tenemos suerte en la conformación de este complejo proceso colectivo, social, cultural, ideológico y político que intenta superar al sistema dominante y sus fallas más ostensibles, se hará sobre la base de una nueva ética y una nueva lógica del funcionamiento social propia de los pueblos, que también se construirán desde abajo.

\section{BIBLIOGRAFÍA}

ALVES DA SILVA, R.M. (2006), Entre o combate à seca e a convivência com o semi-árido. Tesis doctoral. Brasilia, Universidad de Brasilia, en: http://repositorio.unb.br/bitstream/10482/2309/1/2006_R oberto\%20Marinho\%20Alves\%20da\%20Silva.pdf.

DEFOURNY, J., DEVELTERE, P. y FONTENEAU, B. (2001), La Economía social en el Norte y en el Sur, Buenos Aires, Argentina, Corregidor.

FELBER, C. (2012), La Economía del Bien Común, Barcelona, Grupo Planeta, Ediciones Deusto.

FRAISSE, L. (2004), "Economía solidaria y democratización de la economía", en J.L. Laville (ed.), Economía social y solidaria. Una visión europea, Buenos Aires, Fundación OSDE -Universidad Nacional de General Sarmiento- Editorial Altamira.

GALLICCHIO, E. (2004), "El desarrollo económico local en América Latina. ¿Estrategia económica o de construcción de capital social?" en Seminario gobierno local y desarrollo, 28 y 29 de Enero, Barcelona, Centro Latinoamericano de Economía Humana.

GARAFOLI, G. (1992), "Endogenous development and Southern Europe: An introduction" en Endogenous development and Southern Europe, Londres,

GARDIN, L. (2004): "Las empresas sociales", en J.L. Laville (ed.), Economía social y solidaria. Una visión europea, Buenos Aires, Fundación OSDE -Universidad Nacional de General SarmientoEditorial Altamira.

GOMES, R., CASTILLA, T. y BERTUCCI, J. (2012), "La economía solidaria en América Latina y el Caribe. Actores, presencia, experiencias, redes; reflexión y desafíos", en http://www.socioeco. org/bdf/ docs/celam dejusol economia solidaria en america latina.pdf. Consulta 25/10/2012.

LAVILLEE, J.L. (1997), La crise de la condition salariale: emploi, activité et nouvelle question sociale, in Le travai lquel avenir? París, Gallimard, Folio Actuel.

LAVILLE, J.L. (ed.) (2004), Economía social y solidaria. Una visión europea, Buenos Aires, Fundación OSDE -Universidad Nacional de General Sarmiento- Editorial Altamira.

LAVILLE, J.L. (2004), "Los aportes y límites de la economía social", en J.L. Laville (ed.), Economía social y solidaria. Una visión europea, Buenos Aires, Fundación OSDE -Universidad Nacional de General Sarmiento- Editorial Altamira.

LAVILLE, J.L. (2004), "Las aporías del tercer sector", en J.L. Lavilla (ed.), Economía social y solidaria. Una visión europea, Buenos Aires, Fundación OSDE -Universidad Nacional de General Sarmiento- Editorial Altamira.

RAUBER, I. (2006), Sujetos Políticos. Rumbos estratégicos y tareas actuales de los movimientos sociales y políticos. Santo Domingo, República Dominicana, Editorial Pasado y Presente XXI, en http://es.scribd.com/doc/77913529/Isabel-Rauber-Sujetos-Politicos

VÁZQUEZ, B. (2000), "Desarrollo económico local y descentralización: aproximación a un marco conceptual al proyecto CEPAL/GTZ", en Desarrollo económico local y descentralización en América Latina. Santiago de Chile, CEPAL. 


\section{Breve currículo}

\section{Verónica Gómez Calvo}

Doctora en Sociología y Especialista Universitario en Cooperación Internacional para el Desarrollo, Universidad de Alicante. Licenciada en Filosofía y Ciencias de la Educación, especialidad Filosofía, Universidad de Deusto. Profesora titular de la Universidad de Nevada en Reno en su programa de estudios en el extranjero USAC Alicante sito en la Universidad de Alicante. Publicaciones: El Futuro del Sector Confeccionista. Panorámica internacional del sector y su evolución en España y la Comunidad Valenciana y La evolución de la precariedad laboral en la provincia de Alicante. Es coordinadora de la Economía del Bien Común en Alicante, miembro del Comité de Servicios Públicos de ATTAC España, y miembro del equipo redactor del Alter Trade Mandate. 